\title{
Oxidative stress and ageing in Caenorhabditis elegans
}

\author{
Jacques R. VANFLETEREN \\ Laboratory of Animal Morphology and Systematics, University of Ghent, Ledeganckstraat 35, B-9000 Ghent, Belgium
}

\begin{abstract}
Mutations in the age- 1 gene double both the mean and maximum life span of Caenorhabditis elegans. They also result in an agespecific increase of catalase and $\mathrm{Cu} / \mathrm{Zn}$ superoxide dismutase activity levels. The higher superoxide dismutase activity levels in age-1 mutants confer hyperresistance to the superoxide-aniongenerating drug paraquat. The rate of superoxide anion production by microsome fractions declines linearly with age in age-
\end{abstract}

$1(+)$ worms, but, after an initial decline, is stabilized at a higher level in senescent age-1 mutant nematodes. These results clearly show that oxidative stress resistance and potential life span are correlated in this organism, and they suggest that the natural product of age-1 either directly or indirectly downregulates the activities of several other genes as a function of age.

\section{INTRODUCTION}

While senescence is a characteristic feature in metazoans including man, the mechanisms that determine the onset and the progress of this deteriorative process are still unknown. The existence of genetic programmes for ageing have been postulated [1-3], mainly to account for the universal observation that the mean and maximum life spans are species-specific, but rigid experimental evidence supporting such models is lacking. It is also not clear how such ageing genes could be selected for unless they enhance fitness at an earlier stage of the life history. Substantial experimental evidence has been put forward against models of stohastic ageing such as somatic mutation accumulation and error propagation at the level of protein synthesis [4,5]. The freeradical theory of ageing [6,7] has not been found to be inconsistent with experimental data so far. This model advocates that cell and tissue injury by oxygen-derived radicals constitutes, or at least significantly contributes to, the ageing process. The observation that longevity is inversely related to the metabolic rate [8] but positively correlated with the ratio of superoxide dismutase (SOD) activity to metabolic rate [9] in a series of mammalian species is easily explained by the model, but more direct evidence supporting it has remained largely elusive.

Mutant strains that extend both mean and maximum life span in $C$. elegans were isolated recently [10-12]. These strains carry recessive alleles of the age-1 gene. When grown at $25^{\circ} \mathrm{C}$ and in monoxenic association with Escherichia coli, these worms have mean and maximum life spans that are increased by $65 \%$ and $110 \%$ respectively, relative to wild-type worms. Under axenic growth conditions $[13,14]$ these increases are still higher (J. R. Vanfleteren, unpublished work). All the increase in life expectancy is due to an increase in the length of post-reproductive life; a mutation in the age-1 gene does not markedly affect other life history traits such as the rate of development, length of the reproductive period, food uptake, movement, or behaviour [11]. I now report that long-lived age-1 mutants of $C$. elegans have elevated levels of catalase and SOD at old age.

\section{EXPERIMENTAL}

Strains, culture methods and age cohorts

The strains studied were N2 (wild-type strain), which carries the normal alleles of age- 1 and fer-15, BA713 age- $1(+)$ fer-15(b26), which has a temperature-sensitive mutation (b26) that impairs reproduction at the restrictive temperature $\left(25^{\circ} \mathrm{C}\right)$, and the long-lived strains TJ401 age-l(hx546) fer-15(b26), TJ411 age1(hx542) fer-15(b26), and TJ412 age-1(hx542) fer-15(b26). The latter strains represent separate re-isolates obtained by backcrossing MK542 to N2 [10-12]. C. elegans is a small free-living and soil-dwelling nematode, which feeds on bacteria. Adult worms are predominantly hermaphrodites, males occur at very low frequencies $(0.1-0.2 \%)$. The hermaphrodites are proterandrous: they produce first sperm (about 300), then oocytes, which are fertilized by a sperm cell. The zygote develops within the egg shell while the eggs pass through the uterus and the vulva. Juvenile worms develop through four juvenile stages and reach adulthood within 3 days at $21^{\circ} \mathrm{C}$. The adults are fertile for about 4 days in bacterial culture; next they enter the post-reproductive phase of the life cycle, in which symptoms of senescence accumulate. Mean life span is approx. 3-4 weeks at $21^{\circ} \mathrm{C}$ depending on the nutritional regime. The term 'gravid adults' is used here to indicate 1-week-old adult worms harvested from axenic [13,14] (BA713, TJ412) or bacterial precultures (TJ401, TJ411), that were grown at the permissive temperature $\left(15^{\circ} \mathrm{C}\right)$. These worms carried numerous eggs in various stages of embryonic development. Synchronized age cohorts were grown at $25^{\circ} \mathrm{C}$ in xenic culture medium [14] (BA713, TJ412) or on $E$. coli cells (TJ401, TJ411). They contained no (2- and 3-week-old, post-reproductive worms) or almost (1-week-old) no eggs. The designations 1-, 2- and 3-week-old worms are used to improve clarity. The precise age distribution within the cohorts was: BA713, 6-8, 13-15, 18-20 days; TJ412: 6-8, 13-15, 20-22 days; TJ411 and TJ401: 5-6, 13-15, 20 days. Compared with the human population, 1-week-old worms are equal to young reproductive adults, 2-week-old worms to the human 45-65 age class, and 3-week-old worms to senescent people. Worms were washed free of medium using standard techniques [15] and stored at $-80^{\circ} \mathrm{C}$ until use.

\section{Enzyme activity assays}

Thawed worm suspensions were sonicated intermittently on ice for $5 \mathrm{~min}$ at $20 \%$ duty cycle and output control 2 settings (VibraCell, Sonics and Materials, CT). 3-([3-Cholamidopropyl)dimethylammonio]-1-propanesulphonic acid (CHAPS) was 
added to the homogenate at $1 \%(w / v)$ final concentration. Catalase activity was determined according to Aebi [16] (1 unit of activity is defined here as the amount of enzyme which will decompose $1 \mu \mathrm{mol}$ of $\mathrm{H}_{2} \mathrm{O}_{2} / \mathrm{min}$ at $\mathrm{pH} 7$ and $25^{\circ} \mathrm{C}$ ). Glutathione peroxidase was assayed by the method of Flohé and Günzler [17], using butyl hydroperoxide as a substrate. The cytochrome $c$ reduction assay of Crapo et al. [18] was used to monitor SOD activity; 1 unit is expressed as the amount of enzyme causing $50 \%$ inhibition of cytochrome $c$ reduction at $25^{\circ} \mathrm{C}$ in $50 \mathrm{mM}$ potassium phosphate buffer, $\mathrm{pH}$ 7.8. Partially aceylated cytochrome $c$ [19] was used to reduce interference by cytochrome oxidases and reductases. The manganese-containing enzyme was assayed by monitoring the reduction of Nitro Blue tetrazolium in the presence of $10 \mathrm{mM} \mathrm{KCN}$ to suppress the cuprozinc dismutase [20].

\section{Measurement of microsomal superoxide anion production}

Measurement of superoxide anion production by a cytochrome $c$ reduction assay was impossible, even when substituting acetylated cytochrome for the native form, because of the presence of very strong cytochrome $c$ reductase activity in these preparations. Reliable measurements were therefore obtained using a chemiluminescent assay [21]. Over $98 \%$ of the light emitted was inhibitable by exogeneous SOD (from bovine erythrocytes) indicating that superoxide anion production was being measured. The assay medium contained $60 \mathrm{mM}$ potassium phosphate buffer (pH 7.6), $0.12 \mathrm{mM}$ EDTA and $0.12 \mathrm{mM}$ lucigenin, and the assay was started by the addition of $100 \mu \mathrm{l}$ of $1.5 \mathrm{mM}$ NADPH, $54 \mu \mathrm{l}$ of water and $18 \mu \mathrm{l}$ of microsome suspension to $900 \mu \mathrm{l}$ of assay medium in a scintillation vial. The light emitted was calibrated to superoxide anion production by comparing the rate of cytochrome $c$ reduction by the xanthine-xanthine oxidase system [22] with the light produced when exactly identical amounts of xanthine and xanthine oxidase were added to the lucigenin assay medium. A production rate of $2.4 \mathrm{nmol}$ of $\mathrm{O}_{2}{ }^{-{ }^{-}} / \mathrm{ml}$ per min yielded 60190 c.p.m. in the lucigenin assay.

\section{RESULTS}

\section{Glutathione peroxidase actlvity}

No glutathione peroxidase activity could be demonstrated in $C$. elegans tissue. Assaying exogeneous glutathione peroxidase (from bovine erythrocytes) showed no inactivation of the enzymes by inhibitors (including CHAPS) in the homogenates.

\section{Catalase activity}

Catalase activity (Table 1) was much lower in gravid (worms carrying eggs at various stages of embryonic development) relative to non-gravid hermaphrodites of identical age, suggesting that catalase activity in developing eggs must be very low. In the control strain (BA713) catalase activity increased with age in egg-free worms, followed by a sharp decline during the very senescent period of life. A similar increase and subsequent decrease of catalase activity with age has been observed in other organisms also e.g. insects [23]. No decline of catalase activity was observed in any of the long-lived strains. In one experiment (TJ412) a further increase of catalase activity at 3 weeks of age was scored. As TJ412 and TJ411 have the same genotype, representing separate re-isolates obtained by backcrossing MK542 to N2 [10-12], these differences are probably due to environmental factors. The main conclusion from this experiment is, however, that all three strains containing a mutation in the age-1 gene had elevated levels of catalase activity towards the end of their life cycle relative to a control age-1(+) strain.

\section{SOD activity}

Total SOD activity (Table 1) remained essentially unaltered with age in the wild type. The same level of SOD activity was detected in gravid age- 1 mutants and the control age- $1(+)$ strain. However, non-gravid age- 1 mutants of comparable age had higher levels of SOD activity and these tended to increase linearly with age in all three mutant strains examined. As a result 3-week-old age-1 mutant worms had total SOD activities about $250 \%$ of that of the control age-l(+) strain.

Nematodes, like other animals, have two molecular species of SOD, a copper- and zinc-containing enzyme in the cytoplasm and a manganese-containing enzyme which resides in the mitochondria. In order to distinguish the enzyme activities of both species we have also assayed SOD activity in the presence of $10 \mathrm{mM} \mathrm{KCN}$ which totally suppresses all cuprozinc SOD activity, without affecting the mangano enzyme. Cyanide-resistant SOD activity is quite low in $C$. elegans. Most of the values listed in Table 1 for the TJ strains deviate significantly from the corresponding BA713 values. It is possible that there is also a rise in Mn-SOD activity in the long-lived strains. However, these results are somewhat obscured by a background of bacterial SOD activity, contributed by decaying worms. Bacteria have $\mathrm{Fe}$ - and Mn-containing SODs that are resistant to cyanide. Based on results obtained for $E$. coli, we estimate that $1 \%$ of dead worms (these are actually bags of bacteria) contribute approx. $1 \mathrm{unit} / \mathrm{mg}$ of protein of cyanide-resistant SOD activity in the Nitro Blue tetrazolium assay. Dead worms accumulate as the population ages, and it was technically not possible to remove these quantitively (i.e. well below $1 \%$ ) by repeated washings. Thus, there is no firm evidence suggesting a significant increase in the level of nematode $\mathrm{Mn}-\mathrm{SOD}$ with age in age-1 mutants relative to the age- $1(+)$ genotype. Total SOD activity is about 50 -fold higher, when expressed in comparable units of activity, and not at all affected by decaying worms.

These results suggest that mutation in the age-1 gene has no detectable effect on $\mathrm{Cu} / \mathrm{Zn}$-SOD activity during embryonic development, but results in enhanced levels of this enzyme in adult tissue, which then increase further with age. We did not attempt to determine SOD activity during post-embryonic development.

\section{Resistance to paraquat}

The $\mathrm{LC}_{50}$ values for 3 days of exposure of 10-day-old worms were around $10 \mathrm{mM}$ for age-1(+) genotypes and around $30 \mathrm{mM}$ for age- 1 mutants. When assayed at 17 days of age, the $\mathrm{LC}_{50}$ values were in the range of 5-10 mM for age-1(+) genotypes and still around $30 \mathrm{mM}$ for the single age-1 mutant strain assayed (Figure 1). Thus, the higher levels of SOD activity in age-1-mutant worms probably confer hyperresistance to superoxide anions generated by paraquat.

\section{Microsomal superoxide anion production}

Paraquat generates superoxide anions after reduction by cellular NADPH. Thus worms that are metabolically less active might show some sort of hyperresistance to the drug. For that reason, we have also investigated superoxide anion production by microsomal fractions prepared from an age-1 mutant and a 


\section{Table 1 Catalase, glutathione peroxidase, and SOD activities in ageing C. elegans}

The successive entries represent the enzyme activities measured in homogenates made from 1-week-old gravid adults, and 1-, 2-, and 3-week-old egg-free worms. TJ412, TJ411 and TJ401 are long-lived strains. Activity for all enzymes is expressed in units $/ \mathrm{mg}$ of protein. Values are given as \pm S.E.M. for $n$ replicate assays. Significant deviations from the control strain (BA713) are indicated by the proper $P$ significance levels (Student's $t$ test). ${ }^{\star} P=0.05 ;{ }^{\star \star} P=0.01 ;{ }^{\star \star \star} P=0.001$.

\begin{tabular}{|c|c|c|c|c|c|}
\hline \multirow[b]{2}{*}{ Enzyme/age cohort } & \multirow[b]{2}{*}{ Strain ... } & \multicolumn{4}{|c|}{ Enzyme activity (unit/mg of protein) } \\
\hline & & BA713 & TJ412 & TJ411 & TJ401 \\
\hline \multicolumn{6}{|l|}{ Catalase } \\
\hline 1-week-old gravid adult & & $29.7 \pm 2.8(n=5)$ & $31.9 \pm 4.9(n=5)$ & $39.7 \pm 1.5(n=6)^{\star}$ & $43.6 \pm 2.2(n=6)^{\star}$ \\
\hline 1-week-old egg-free & & $60.4 \pm 6.2(n=5)$ & $79.1 \pm 5.0(n=5)^{\star}$ & $65.3 \pm 3.3(n=4)$ & $73.6 \pm 0.6(n=4)$ \\
\hline 2-week-old egg-free & & $80.0 \pm 3.9(n=6)$ & $79.5 \pm 2.0(n=5)$ & $73.4 \pm 3.4(n=4)$ & $77.6 \pm 1.6(n=4)$ \\
\hline 3-week-old egg-free & & $53.1 \pm 2.7(n=5)$ & $102.1 \pm 5.6(n=6)^{\star \star \star}$ & $72.4 \pm 0.5(n=5)^{\star \star \star}$ & $77.0 \pm 3.2(n=4)^{\star \star \star \star}$ \\
\hline \multirow{2}{*}{\multicolumn{6}{|c|}{ Glutathione peroxidase ( $n=3$ throughout): nil }} \\
\hline & \multicolumn{5}{|c|}{$\operatorname{SOD}(\mathrm{Cu} / \mathrm{Zn}+\mathrm{Mn}$ protein $) \dagger$} \\
\hline 1-week old gravid & & $9.9 \pm 0.4(n=7)$ & $10.3 \pm 0.4(n=11)$ & $10.5 \pm 0.5((n=5)$ & $8.3 \pm 0.9(n=5)$ \\
\hline 1-week-old egg-free & & $10.2 \pm 0.4(n=7)$ & $14.6 \pm 0.9(n=9)^{\star \star}$ & $15.2 \pm 1.5(n=5)^{\star \star}$ & $16.3 \pm 0.8(n=5)^{\star \star \star \star}$ \\
\hline 2-week-old egg-free & & $9.3 \pm 0.8(n=8)$ & $18.5 \pm 1.0(n=8)^{\star \star \star}$ & $19.3 \pm 2.6(n=5)^{\star \star \star}$ & $22.2 \pm 2.2(n=5)^{\star \star \star}$ \\
\hline 3-week-old egg-free & & $10.3 \pm 0.5(n=6)$ & $24.0 \pm 1.6(n=9)^{\star \star \star}$ & $25.2 \pm 1.8(n=5)^{\star \star \star}$ & $25.3 \pm 1.8(n=5)^{\star \star \star}$ \\
\hline \multicolumn{6}{|c|}{ SOD (Mn protein) $\ddagger(n=3$ throughout) } \\
\hline 1-week-old gravid & & $1.2 \pm 0.1$ & $0.9 \pm 0.1^{*}$ & $1.5 \pm 0.1^{\star}$ & $1.6 \pm 0.1^{\star}$ \\
\hline 1-week-old egg-free & & $1.0 \pm 0.1$ & $1.2 \pm 0.1^{*}$ & $1.3 \pm 0.1^{\star \star}$ & $1.7 \pm 0.1^{\star \star \star \star}$ \\
\hline 2-week-old egg-free & & $1.0 \pm 0.1$ & $1.2 \pm 0.1^{\star}$ & $1.7 \pm 0.1^{\star \star \star \star}$ & $1.9 \pm 0.1^{\star \star \star}$ \\
\hline 3-week-old egg-free & & $1.5 \pm 0.1$ & $1.9 \pm 0.1^{\star \star}$ & $2.0 \pm 0.1^{\star \star}$ & $2.4 \pm 0.1^{\star \star \star}$ \\
\hline
\end{tabular}

$\dagger$ The assay using acetylated cytochrome $c$ (Ac-cyt $c$ ) is more sensitive relative to native cytochrome $c$, yielding approx. 2.5 units of activity for 1 unit using native cytochrome $c$.

¥ This assay was approx. 5 times more sensitive than the Ac-cyt $c$ assay. Thus 1 unit of Mn-SOD activity represents approx. 0.2 unit of activity in the total SOD assay.

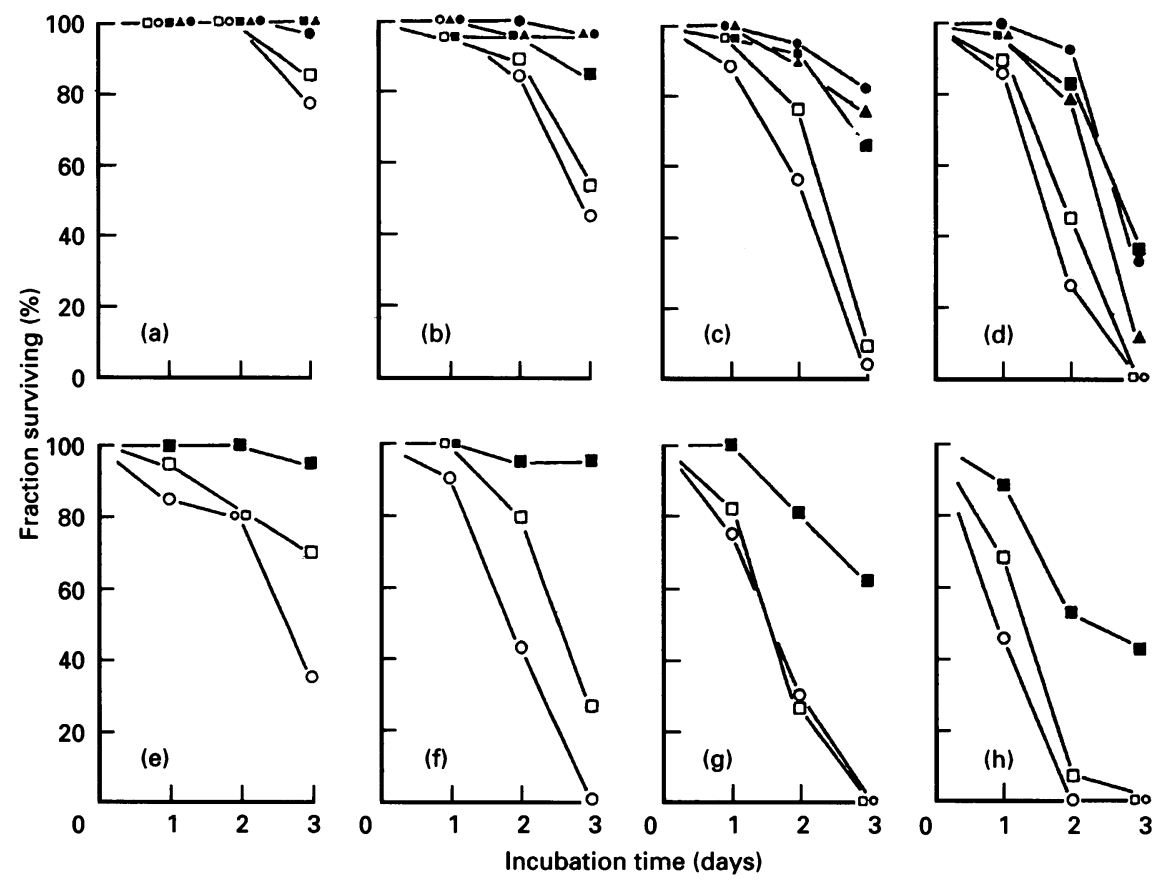

\section{Figure 1 Sensitivity to paraquat as a function of strain and age differences}

(a-d) Ten-day-old worms exposed to $5 \mathrm{mM}(\mathbf{a}), 10 \mathrm{mM}$ (b), $20 \mathrm{mM}$ (c) and $40 \mathrm{mM}$ (d) paraquat for 1-3 days; (o-h) 17-day-old worms exposed to $5 \mathrm{mM}(\mathbf{e}), 10 \mathrm{mM}(\mathbf{f}), 20 \mathrm{mM}(\mathbf{g})$ and $40 \mathrm{mM}$ (h) paraquat. Worms were grown and assayed in the standard axenic culture medium at $25^{\circ} \mathrm{C}$. N2 was also grown and assayed in the presence of $50 \mu \mathrm{M} 5$-fluorodeoxyuridine to block progeny development. O, N2; $\square$, BA713; $\square$, TJ412; $\mathbf{\Delta}$, TJ401; ○, TJ411.

control strain as a measure of metabolic activity (Table 2). In 1to 3-week-old age-1(+) worms, superoxide anion production decreased linearly with age to reach $25 \%$ of the original level in the senescent stage. This trend was quite similar in long-lived worms up to 2 weeks of age, then superoxide production became stabilized, reaching $45 \%$ of the original level in 3-week-old worms, a level significantly higher than that of the wild type. 


\section{Table 2 Superoxide anion production by mocrosomes as a function of age}

The successive entries represent superoxide anion production by microsomal fractions from 1(non-gravid)-, 2- and 3-week-old worms, expressed as nmol of $0_{2}{ }^{--}$per $\mathrm{mg}$ of microsomal protein. TJ412, long-lived strain, BA713, control.

\begin{tabular}{lll}
\hline Strain & $\begin{array}{l}\text { Superoxide anion production } \\
\left(\mathrm{nmol} \mathrm{O}_{2}^{--} / \mathrm{mg} \text { per } \mathrm{min}\right)\end{array}$ & $\begin{array}{l}\text { SOD activity* } \\
\text { (unit/mg of protein) }\end{array}$ \\
\hline \multirow{2}{*}{ BA713 } & $39.5 \pm 0.7$ & $2.7 \pm 0.1$ \\
& $22.1 \pm 2.3$ & $3.1 \pm 0.4$ \\
TJ412 & $10.2 \pm 2.8$ & $2.5 \pm 0.3$ \\
& $40.1 \pm 0.9$ & $3.5 \pm 0.2$ \\
& $23.1 \pm 4.2$ & $2.8 \pm 0.2$ \\
& $18.0 \pm 2.1 \dagger$ & $3.1 \pm 0.1$
\end{tabular}

* Denotes the residual SOD activity (acetylated cytochrome $c$ reduction assay); enzyme molecules trapped within the microsomal vesicles cannot be removed by washing.

$\dagger P<0.05$ when compared with 3-week-old BA713.

\section{DISCUSSION}

While generally regarded as a main component of vertebrate oxygen defence, the presence of glutathione peroxidase could not be demonstrated in C. elegans tissue. Activity of this enzyme was also reported to be undetectable in Ascaris [24], pupae of fleshfly and Chinese oak silk moth [25] and in house fly [23,26]. A low level of glutathione peroxidase activity in several insect species was reported by Ahmed et al. [27], but these results were questioned by Sohal et al. [23].

Larsen and Varshavsky (unpublished work) observed that senescent TJ401 (fer-15, age- 1 ) were hyperresistant to $\mathrm{H}_{2} \mathrm{O}_{2}$. The present results suggest that catalase, $\mathrm{Cu} / \mathrm{Zn}-\mathrm{SOD}$ and the enzyme activities involved in superoxide anion production are all pushed to higher levels in senescent age-1 mutants relative to age-1(+) genotypes. This is consistent with a model in which the normal age- 1 product is a protein, which downregulates the activity of several other genes as a function of age. The molecular cloning and analysis of the age-1 gene may shed more light on how this regulation is achieved. These results also show that oxidativestress defence and potential life span are closely correlated in $C$. elegans. They are compatible with the general hypothesis that the balance between oxidative stress and the antioxidant defence determines the potential life span, a hypothesis which is also corroborated by the 4.5 -fold elevation of SOD activity in dauer larvae (non-aging diapause stage) of C. elegans [28], but they fail to prove this model unequivocally. For example, the increased resistance to reactive-oxygen species and the longer life demonstrated in age-1 mutants of $C$. elegans may independently result from enhanced protein turnover.

While the present findings are highly compatible with the hypothesis that natural selection acts in the direction of optimizing rather than maximizing longevity [29], it is not clear how the wild-type age-1 gene contributes to the organism's fitness. Age-1 was originally interpreted as an example of negative pleiotropy, as recessive mutations in it were assumed to reduce fertility by $75-80 \%$; i.e. the wild-type gene was believed to increase reproductive fitness of the nematode by approx. 4-5fold, at the cost of a considerable reduction in life expectancy $[11,12]$. However, the long-life trait was recently successfully separated from both fer-15 and the low fertility trait (T. Hutchinson, P. Tedesco and T. Johnson, unpublished work), thus abolishing any clear evidence for a trade off between survival and fecundity. Further work in this field, in particular the isolation and mapping of other 'age' mutations undoubtedly will add to our understanding of the dynamics of the ageing process and the evolution of senescence.

I thank T. E. Johnson for providing strains and for stimulating discussions. The skifful technical assistance of Mrs. A. M. Waelkens-De Vreese is gratefully acknowledged. This work was supported by Grant no. 2.0003.90 from the Fund for Joint Basic Research and Grant no. 01130790 from the Onderzoeksfonds U.G.

\section{REFERENCES}

1 Wilson, D. L. (1974) in Theoretical Aspects of Aging (Rockstein, M., ed.), pp. 11-21, Academic Press, New York

2 Hill, B. and Franks, L. M. (1977) Trends Biochem. Sci. 2, N80-N82

3 Shock, N. W. (1981) in Handbook of Biochemistry in Aging (Florini, J. R., ed.), pp. 271-279, CRC Press, Boca Raton, Florida

4 Hayflick, L. (1985) Exp. Gerontol. 20, 145-159

5 Rothstein, M. (1982) Biochemical Approaches to Aging, Academic Press, New York

6 Harman, D. (1981) Proc. Natl. Acad. Sci. U.S.A. 78, 7124-7128

7 Sohal, R. S. and Allen, R. G. (1990) Exp. Gerontol. 25, 499-522

8 Cutler, R. G. (1978) in The Biology in Aging (Behnke, J. A., Finch, C. E. and Moment, G. B., eds.), pp. 311-360, Plenum Press, New York

9 Tolmasoff, J. M., Ono, T. and Cutler, R. G. (1980) Proc. Natl. Acad. Sci. U.S.A. 77, 2777-2781

10 Klass, M. R. (1983) Mech. Ageing Develop. 22, 279-286

11 Friedman, D. B. and Johnson, T. E. (1988) Genetics 118, 75-86

12 Friedman, D. B. and Johnson, T. E. (1988) J. Gerontol. 43, B102-B109

13 Vanfleteren, J. R. (1980) in Nematodes as Biological Models. Aging and Other Model Systems (Zuckerman, B. M., ed.), vol. 2, pp. 47-49, Academic Press, New York

14 Vanfleteren, J. R., Van Bun, S. M., De Baere, I. and Van Beeumen, J. J. (1990) Biochem. J. 265, 739-746

15 Wood, W. B. (ed.) (1988) The Nematode Caenorhabditis elegans, Cold Spring Harbor Laboratory, New York

16 Aebi, H. (1984) Methods Enzymol. 105, 121-126

17 Flohé, L. and Günzler, W. A. (1984) Methods Enzymol. 105, 114-121

18 Crapo, J. D., McCord, J. M. and Fridovich, I. (1978) Methods Enzymol. 53, 382-393

19 Azzi, A., Montecucco, C. and Richter, C. (1975) Biochem. Biophys. Res. Commun. 65, 597-603

20 Oberley, L. W. and Spitz, D. R. (1984) Methods Enzymol. 105, 475-464

21 Corbisier, P., Houbion, A. and Remacle, J. (1987) Anal. Biochem. 164, 240-247

22 Hassan, H. M. (1984) Methods Enzymol. 105, 404-412

23 Sohal, R. S., Arnold, L. and Orr, W. (1990) Mech. Ageing Develop. 56, 223-225

24 Lesoon, A., Komuniecki, P. R. and Komuniecki, R. (1990) Comp. Biochem. Physiol. 95B, $811-815$

25 Smith, J. and Shrift, A. (1979) Comp. Biochem. Physiol. 63B, 39-44

26 Simmons, T. W., Jamall, I. S. and Lockhin, R. A. (1989) Comp. Biochem. Physiol. 94B, 323-327

27 Ahmed, S., Beilstein, M. A. and Pardini, R. S. (1989) Arch. Insect Biochem. Physiol. 12, $31-49$

28 Anderson, G. L. (1982) Can. J. Zool. 60, 288-291

29 Kirkwood, T. B. L. and Rose, M. L. (1991) Phil. Trans. R. Soc. London. B 322, $15-24$ 